\title{
Neem (Azadirachta indica) Leaves for Removal of Organic Pollutants
}

\author{
Muhammad B. Ibrahim 1,2, Sadiq Sani3 \\ ${ }^{1}$ Department of Pure and Industrial Chemistry, Bayero University, Kano, Nigeria \\ ${ }^{2}$ Umaru Musa Yar'adua University, Katsina, Nigeria \\ ${ }^{3}$ Department of Applied Chemistry, Federal University Dutsin-Ma, Katsina, Nigeria \\ Email: mbibrahim.chm@buk.edu.ng
}

Received July 2014

Copyright (C) 2015 by authors and Scientific Research Publishing Inc.

This work is licensed under the Creative Commons Attribution International License (CC BY). http://creativecommons.org/licenses/by/4.0/

(c) (i) Open Access

\section{Abstract}

Neem (Azadirachta indica) leaves was employed in a batch adsorption technique for the detoxification of congo red (CR) and methyl orange (MO) dyes from a single component model wastewater. The adsorption efficiency of the leave was judged based on changes of parameters like agitation time, adsorbent dosage, adsorbent particle size, and adsorbate initial concentration and $\mathrm{pH}$. Adsorbate concentration during the adsorption process was monitored using T60-U UV-Visible spectrometer from TG Instruments. While FTIR and SEM were employed to study the surface functional group and morphological changes of the adsorbent before and after the adsorption process. Percent adsorption increased with increase in agitation time (5 - 240 minutes), adsorbent dosage $(0.1-0.5 \mathrm{~g})$, initial concentration $(100-300 \mathrm{mg} / \mathrm{L})$, and with decrease in particle size $(\geq 75 \mu \mathrm{m}$ to $\leq 300 \mu \mathrm{m}$ ) of adsorbent. The adsorption processes were found to be $\mathrm{pH}$-dependent, increasing or decreasing in acidic (pH 2 - 6) or alkaline (pH 8 - 12) range over the studied pH (2 - 12) range. The correlation coefficient $\left(\mathrm{R}^{2}\right.$ - values) ranging from 0.9359 - 0.9998 shows good agreement of the experimental data for all the tested isotherms. The monolayer maximum adsorption capacity for Langmuir's $q_{m}(18.62-24.75 \mathrm{mg} / \mathrm{g})$ and Dubinin-Radushkevich, $q_{D}(20.72-26.06 \mathrm{mg} / \mathrm{g})$ are comparable. Both Langmuir's separation factor $\left(R_{L}\right)$ and Freundlich constant $\left(n_{F}\right)$ suggests unfavourable adsorption of the dyes onto the adsorbent. The mean free energy of adsorption, $E$ (79.06 $316.23 \mathrm{~J} / \mathrm{mol}$ ) calculated from Dubinin-Radushkevich equation suggest a physical adsorption. Restricted range of values for heat of adsorption, $b_{\mathrm{T}}(-946.9$ to $737.4 \mathrm{~J} / \mathrm{mol})$, was obtained from Temkin equation. Reduction in band intensities and vibrational changes observed in FTIR spectra indicate possible involvement of carbonyl $(-\mathrm{C}=0)$, carboxyl $(-\mathrm{COOH})$, hydroxyl alcoholic $(-\mathrm{OH})$ and amino $\left(-\mathrm{NH}_{2}\right)$ functional groups on the adsorbents' surfaces during the adsorption and interaction with the sulfonic acid groups $\left(-\mathrm{SO}_{3} \mathrm{H}\right)$ on the adsorbate molecules. The difference in irregular and porous texture surface morphology of fresh and dye-loaded adsorbents characterized the adsorption of the dyes by neem leaves. The study shows that neem leaves are potential alternative low-cost adsorbents for the effective removal of Congo red (CR) and Methyl orange (MO) from 
wastewater.

Keywords

Batch Adsorption, Congo Red, Dye, Isotherms, Neem Leaves, Methyl Orange, Wastewater

\section{Introduction}

Water is an essential for human survival and occupying $71 \%$ of the earth surface of which only about $0.05 \%$ is accessible for consumption. The bulk of the rest comprises of seawater, groundwater, swamps and frozen polar ice caps. Its demand doubles every 21 years globally, affecting $40 \%$ of world population. Thus, exploitation of safe water sources and water scarcity are global challenges that receive much attention from government and private organizations [1] [2].

Wastewaters, high in organic and inorganic materials (dyes, phenolic compounds, aromatic compounds and heavy metals) can be reclaimed from industrial effluents, municipal wastewater, agricultural return flows and storm water by different methods depending on its constituents [3]. The untreated effluents discharged from industries (textile, cosmetics, pulp and paper, paint, pharmaceutical, food, carpet and printing) are highly colored due to large amounts of unfixed dyes that remained during coloring and washing [4]. Almost all dyes in use today are synthetic with annual production of over $7 \times 10^{5}$ tonnes of which azo dyes account for $60 \%-70 \%$ [5]. About $10-15 \%$ of these dyes are discharged as effluents during the dyeing process [6] [7]. The effluent could leach into surface and ground waters used for drinking; affect the photosynthesis of aquatic plants by hindering penetration of light into the water; and may cause suffocation of aquatic flora and fauna due to anaerobic degradation of azo dyes into highly lethal substances [8]-[10].

Most often the available techniques for removal of dyes from wastewaters are ineffective (or poorly employed), expensive, complicated, time-consuming and require highly-skilled personnel especially when the levels of dissolved dyes are in the range of $1-100 \mathrm{mg} / \mathrm{L}$. This has stimulated the search for cheaper and easy to use alternatives [11]. Adsorption techniques (either batch or dynamic) have been found to be promising for pollutant removal from wastewaters [12] [13]. Thus, this work aimed at studying the adsorption behavior of neem leaves for the removal of Congo Red (CR) and Methyl Orange (MO) dyes.

\section{Materials and Methods}

\subsection{Materials}

Neem (Azadirachta indica) leaves were collected from twigs of a number of matured trees within and near the main campus of Umaru Musa Yar'adua University, Katsina. The leaves were excessively washed with tap-water followed by rinsing with distilled water to remove dust and any other soluble substances. They were allowed to air dry under shade at room temperature until they become crisp. The dried leaves were then pulverized with a mechanical grinder; and then dried overnight for 16 hours in an oven at a temperature range of $65^{\circ} \mathrm{C}$. The oven-dried samples was then sieved into the working size of 75 - $300 \mu \mathrm{m}$ range using electronic shaker and the fractions preserved in separately labeled air-tight plastic containers for subsequent use [14].

Analytical grade (Congo Red and Methyl Orange) dyes from BDH were used as received without any purification. Stock solutions were prepared by dissolving $1 \mathrm{~g}$ of each dye in a $1000 \mathrm{~cm}^{3}$ volumetric flasks to make $1000 \mathrm{mg} / \mathrm{L}$ of the dye solution [15]. Working and calibration standards were prepared by seriel dilutions.

\subsection{Methods}

Fourier Transform Infra Red (FTIR) spectroscopy was conducted on both the raw adsorbent and the adsorbate loaded adsorbent using CARY 630 FTIR spectrophotometer from Agilent Technologies with the view to identify the different functional groups responsible for the adsorbate adsorption; and there possible changes thereafter. Similarly, Scanning Electron Microscopy (SEM) was carried out on the adsorbent before and after the adsorption using a Philips XL30 Scanning Electron Microscope at accelerating voltage of $15 \mathrm{kV}$, beam size 3.0, working distance 10 and magnification $(2000 \times)$ in order to analyze possible changes on the morphological and sur- 
face characteristics of the adsorbent as a result of the adsorption process.

Batch adsorption studies were conducted by mixing various amounts of adsorbent $(0.1-0.5 \mathrm{~g})$ of different particle sizes ( $\geq 75 \mu \mathrm{m}, \leq 150 \mu \mathrm{m}, \leq 250 \mu \mathrm{m}, \leq 300 \mu \mathrm{m}$ and $>300 \mu \mathrm{m}$ ), in $250 \mathrm{~cm}^{3}$ Erlenmeyer flasks containing 50 $\mathrm{cm}^{3}$ of dye solution of known concentration $(5-300 \mathrm{mg} / \mathrm{L})$. The initial $\mathrm{pH}$ of the dye solutions were adjusted to the working values ( $\mathrm{pH} 2-12$ ) by adding few drops of $0.1 \mathrm{M} \mathrm{HCl}$ or $0.1 \mathrm{M} \mathrm{NaOH}$ aqueous solutions. The solutions were agitated using orbital shaker at $300 \mathrm{rpm}$ and room temperature $\left(30^{\circ} \mathrm{C} \pm 2^{\circ} \mathrm{C}\right)$ for a series of contact time (5 - $120 \mathrm{~min})$ to attain equilibrium. At the end of the equilibrium time intervals, the samples were taken out and the supernatant solution was separated from the adsorbent by filtration with Whatman No. 41 filter paper, discarding the first few volume (3 - 4 drops) of the filtrate [16]. The filtrates were used for analyses using UVVisible spectrophotometer at $\lambda_{\max }$ of 496.5 and $464 \mathrm{~nm}$ for congo red and methyl orange respectively, reporting each data point as an average value of triplicates readings. Percentage dye adsorption and equilibrium adsorption capacity, $q_{e}(\mathrm{mg} / \mathrm{g})$ were evaluated using the equations;

$$
\begin{gathered}
\text { \% Adsorption }=\left(\frac{C_{o}-C_{e}}{C_{o}}\right) \times 100 \\
q_{e}=\frac{V\left(C_{o}-C_{e}\right)}{w}
\end{gathered}
$$

where $C_{o}(\mathrm{mg} / \mathrm{L})$ is the initial dye concentration, $C_{e}$ is the concentration at equilibrium or predetermined time t, $V(\mathrm{~L})$ is the volume of dye solution used and $W(\mathrm{~g})$ is the weight of the adsorbent.

\section{Results and Discussion}

\subsection{Agitation Time}

Agitation time is an important parameter that affects all transfer phenomena including adsorption process [17]. With increased agitation time, the rate of diffusion of the dye molecules from bulk liquid to the liquid boundary layer surrounding the adsorbent particles becomes higher due to enhanced turbulence and decreased thickness of the liquid boundary layer [16].

Studies on the effect of agitation time (5 - 240 minutes) on the percent adsorption of the dyes (CR and MO) onto NLP adsorbent were carried out (Figure 1). On the onset of the process, the percent adsorption of both dyes onto NLP was rapid with CR attaining an optimum value of $99.70 \%$ in 15 minutes and an equilibrium value of $96.32 \%$ at 45 minutes. While $\mathrm{MO}$ attained an optimum value (83.33\%) in 45 minutes and equilibrium value $(64.79 \%)$ at 120 minutes.

According to Lian et al. [18] in his work for the adsorption of congo red onto Ca-bentonite surface, the relatively high removal of the dye initially by the adsorbent could be attributed to the availability of large number of vacant sites for adsorption of Congo red and methyl orange onto surfaces of the adsorbents. While at a later time, the process becomes relatively slower as it approaches equilibrium conditions until equilibrium is achieved at a given time [19]. At this time, the amount of the dye desorbing from the adsorbent is in a state of dynamic equilibrium with the amount of the dye being adsorbed, which reflects the maximum adsorption capacity of the adsorbent under the working conditions [19].

\subsection{Effect of Adsorbent Dosage}

Effects of adsorbents dosage ( $0.1-0.5 \mathrm{~g})$ on percent adsorption of the dyes (Figure 2) revealed that the percent adsorption of CR onto the adsorbent varied from $75.10 \%-91.57 \%$ while MO varied from $23.81 \%-57.23 \%$. As amount of adsorbent increases, number of active sites available for adsorption also increases, thus increasing the percent removal for the dyes. At the minimum dosage $(0.1 \mathrm{~g})$ there was diminutive availability of exchangeable sites which in turn led to removal of minimum amounts of dyes, while at maximum dosage $(0.5 \mathrm{~g})$ there was greater availability of exchangeable sites which ultimately led to the removal of maximum amounts of dyes [17].

\subsection{Effect of Adsorbent Particle Size}

Generally, as the adsorbent particle sizes decrease (from $300 \mu \mathrm{m}$ to $75 \mu \mathrm{m}$ ) the surface area increases leading to incresaed adsorption of dye molecules (Figure 3). Percent adsorption of Congo red varied from $91.71 \%-83.41 \%$ 


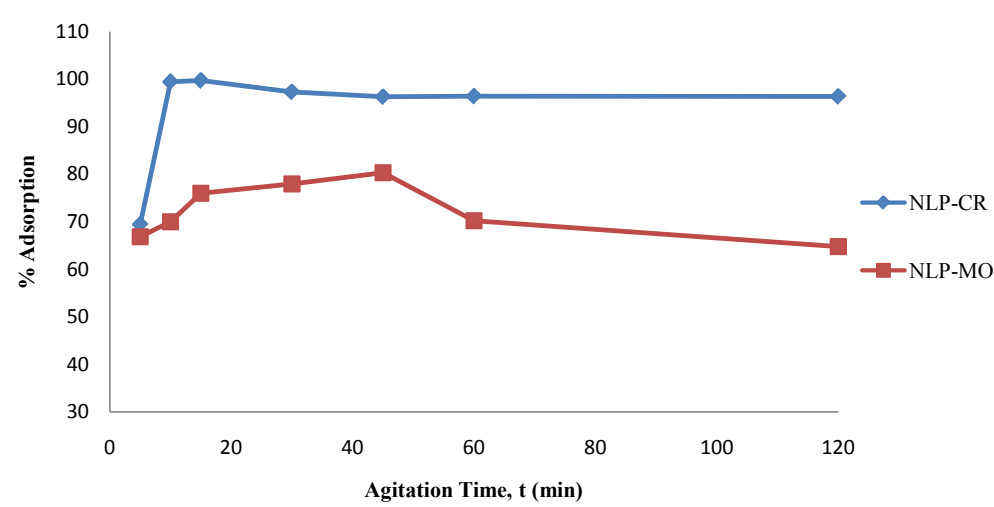

Figure 1. Variation of $\%$ adsorption with agitation time.

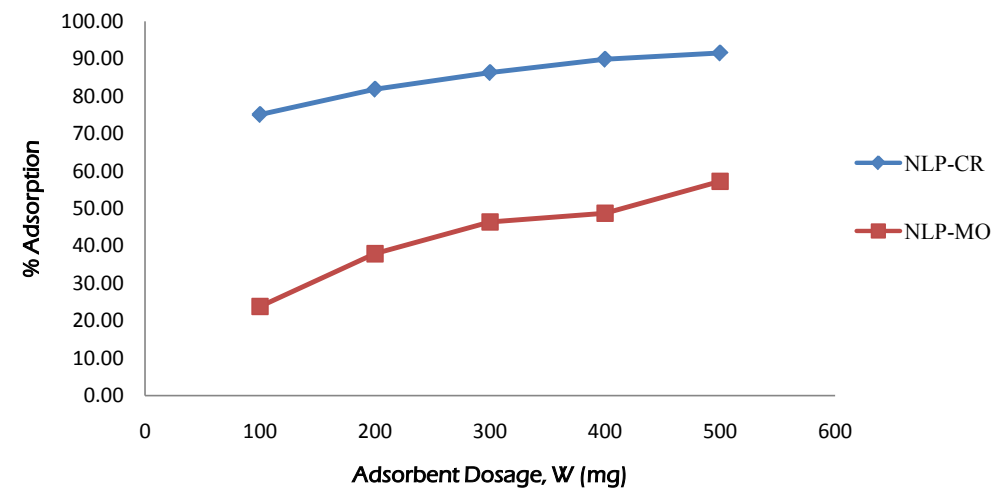

Figure 2. Variation of \% Adsorption with Adsorbent Dose.

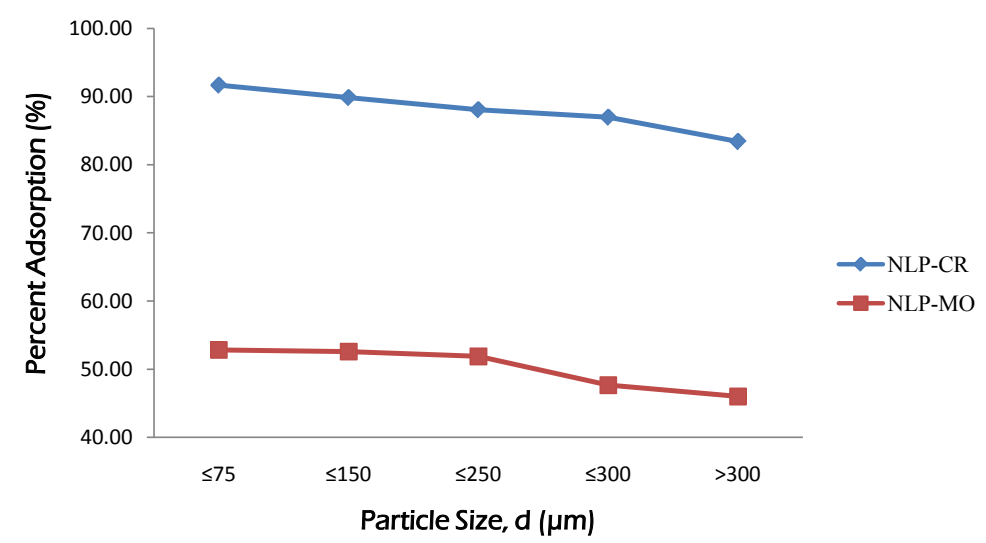

Figure 3. Variation of $\%$ adsorption with particle size.

while that of methyl orange varied from $52.83 \%-46.01 \%$. This can be attributed to the fact that the larger particle sizes have widened diffusion path and decreased total surface area that lowers the ability of the dye to penetrate the entire internal pore structures of the adsorbents while the smaller particle sizes have shortened diffusion path and increased total surface area that makes the ability of the dye to penetrate all the internal pore structures of the adsorbents very high [16].

\subsection{Effect of Initial Concentration}

Studies on the effect of adsorbates loading concentration $(5-300 \mathrm{mg} / \mathrm{L})$ on the percent adsorption of the dyes (Figure 4) showed CR adsorption to increase $(21.19 \%$ - 86.69\%) from 5 to $100 \mathrm{mg} / \mathrm{L}$ and then slowly $(86.69 \%$ - 


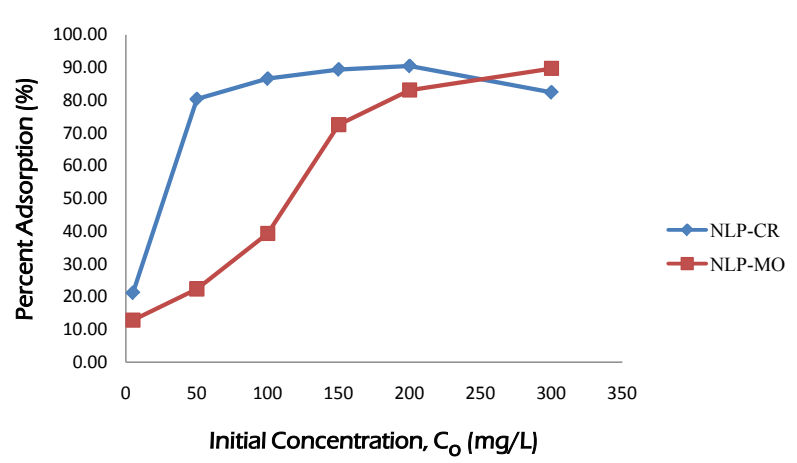

Figure 4. Effect of variation of initial concentration of \% adsorption.

$90.48 \%$ ) from 100 to $200 \mathrm{mg} / \mathrm{L}$ before it decreased to $82.43 \%$ at $300 \mathrm{mg} / \mathrm{L}$ loading concentration. Similarly, adsorption of MO indicated relatively rapid increase $(12.87 \%$ - 90.14\%) within the same range of initial concentrations.

This observation may be as a result of the fact that increase in concentration enhances the interaction between the dye and the adsorbent apart from providing the necessary driving force that overcomes the resistance to the mass transfer of the dyes from aqueous phase onto the surface of the adsorbents [16].

\subsection{Effect of Initial pH}

At lower $\mathrm{pH}$ (i.e. high $\mathrm{H}^{+}$concentration) the percent adsorption as compared in Figure 5 showed removal of $\mathrm{CR}$ to increased fast from $88.39 \%$ at $\mathrm{pH} 2$ to an optimum value of $93.70 \%$ at $\mathrm{pH} 7$ and then decreased to 92.07 at $\mathrm{pH}$ 12. Similarly, percent adsorption of MO increased from $79.87 \%$ at $\mathrm{pH} 2$ until it attained an optimum value of $87.92 \%$ at $\mathrm{pH} 4$ and later decreased to $81.86 \%$ at $\mathrm{pH} 12$. This observation of rapid increase in percent adsorption for the anionic dyes onto neem leaves were similar to that reported by Abdullah et al. [20] for the adsorption of anionic dyes such as methyl orange onto Lapindo volcanic mud (LVM). The variations in the $\mathrm{pH}$ values from acidic to alkaline medium makes both the degree of ionization of dye molecules and the surface properties of the adsorbent to vary which in turn affect the adsorption rate of dyes. Therefore, performing the adsorption in the acidic medium would increase the positive charge on the adsorbent surface causing an increase in the electrostatic attraction between anionic dye molecules (CR-dye and MO-dye) and the surface of adsorbents; hence, the increased rate of adsorption of the dyes (CR and MO).

On the other hand, the presence of high concentration of hydroxyl ions $\left(\mathrm{OH}^{-}\right)$on the adsorbents in the basic medium at $\mathrm{pH}$ range of $8-12$ compete effectively with the dye molecules leading to decreased percent adsorption for both dyes onto the surface of the adsorbent.

\subsection{Adsorption Isotherms}

Based on the various linear relationship of the different isotherms tested (Figures not Included) adsorption isotherm parameters were calculated and tabulated in Table 1.

As shown in the table, the values of linear regression coefficient $\left(R^{2}\right)$ for Langmuir isotherm are located in the range of $0.9989-0.9998$, suggesting that the experimental data follow the Langmuir monolayer adsorption [21]. The calculated $\mathrm{R}_{\mathrm{L}}$ values varies in the order NLP-MO $(-0.0250)<$ NLP-CR $(-0.0078)$ in either case, the negative value shows unfavourable adsorption process [22] [23]. This may be attributed to the decrease in adsorption capacity of adsorbent brought about by decrease in charge density of the dyes during adsorption [24]. The mean values of monolayer adsorption capacity $\mathrm{q}_{\mathrm{m}}$ were found to increase in the order NLP-MO $(21.23 \mathrm{mg} / \mathrm{g})<$ NLP-CR $(24.81 \mathrm{mg} / \mathrm{g})$ which are generally lower than values in the range $41.24-128.26 \mathrm{mg} / \mathrm{g}$ for the removal of Congo red from aqueous medium onto neem leaves [22] and $404.4 \mathrm{mg} / \mathrm{g}$ for removal of methyl orange onto Pine-cone activated carbon [25]; higher than $5.94 \mathrm{mg} / \mathrm{g}$ for the adsorption of Congo red onto kaolin [26]; it is comparable to $20.5 \mathrm{mg} / \mathrm{g}$ and $21 \mathrm{mg} / \mathrm{g}$ for adsorption of methyl orange onto orange peel and banana peel respecttively; $22.86 \mathrm{mg} / \mathrm{g}$ for adsorption of Congo red onto burnt clay [27] and 20.20 for Congo red adsorption onto algae Valoria bryopsis carbon [28].

The regression coefficient $\left(R^{2}\right)$ for the Freundlich isotherm ranged between $0.9910-0.9956$; and the values of $\mathrm{n}_{\mathrm{F}}$ were both greater than 1 demonstrating that the experimental data fitted well to the Freundlich isotherm. The 


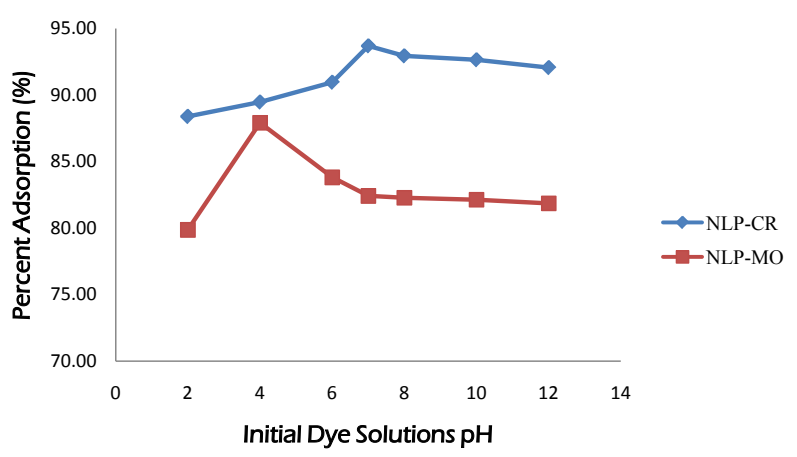

Figure 5. Effect of Initial $\mathrm{pH}$ of the Adsorbate on \% Adsorption.

Table 1. Adsorption Isotherm Parameters for theAdsorption of CR and MO by Neem Leaves.

\begin{tabular}{cccc}
\hline Isotherms & Parameters & \multicolumn{2}{c}{ Adsorbate } \\
\hline Langmuir & & Congo Red & Methyl Orange \\
\hline & $\mathrm{q}_{\mathrm{m}}(\mathrm{mg} / \mathrm{g})$ & 24.81 & 21.23 \\
& $\mathrm{~K}_{\mathrm{L}}$ & -0.4306 & -0.1365 \\
& $\mathrm{R}_{\mathrm{L}}$ & -0.0078 & -0.0250 \\
Freundlich & $\mathrm{R}^{2}$ & 0.998 & 0.9989 \\
& $\mathrm{n}_{\mathrm{F}}$ & 3.7 & 5.47 \\
& $\mathrm{~K}_{\mathrm{F}}$ & 37.3488 & 50.9732 \\
Temkin & $\mathrm{R}^{2}$ & 0.9919 & 0.9910 \\
& $\mathrm{~b}_{\mathrm{T}}(\mathrm{kJ} / \mathrm{mol})$ & 0.7374 & -0.5362 \\
& $\mathrm{~B}_{\mathrm{T}}$ & -2.6164 & -4.6209 \\
& $\mathrm{~A}_{\mathrm{T}}$ & $1.11 \times 10^{-6}$ & $9.06 \times 10^{-5}$ \\
& $\mathrm{R}^{2}$ & 0.9932 & 0.9937 \\
Dubinin-Radushkevich & $\mathrm{B}_{\mathrm{D}}\left(\mathrm{mol} / \mathrm{J}^{2}\right)$ & $5 \times 10^{-6}$ & $3 \times 10^{-5}$ \\
& $\mathrm{E}(\mathrm{kJ} / \mathrm{mol})$ & 0.3162 & 0.1291
\end{tabular}

adsorption process is said to be favourable, non-specific adsorption on heterogeneous surfaces [21] [29].

The relevant Temkin isotherm parameters (Table 1) indicate that the values of $R^{2}$ are positioned within 0.9932 - 0.9937 , which gave a close fit for the CR and MO adsorption onto the adsorbent. Furthermore, it can also be observed that the adsorption heat was restricted within -0.5362 to $0.7374 \mathrm{~kJ} / \mathrm{mol}$.

The Dubinin-Radushkevich (D-R) isotherm plot was obtained corresponding to which the isotherm parameters are calculated and summarized in Table 1. The values of linear regression coefficient $\left(R^{2}\right)$ are in the range of $0.9359-0.9724$, revealing that the experimental data fitted well with the Dubinin-Radushkevich (D-R) isotherm model. Moreover, it is reported that, when the value of $E$ is below $8 \mathrm{~kJ} / \mathrm{mol}$, the adsorption process can be considered as the physical adsorption. In contrast, if the value of $E$ is located in the range of $8-16 \mathrm{~kJ} / \mathrm{mol}$, it is the chemical adsorption. From the table, it can be observed that the obtained values of mean free energy, $E$, are limited within the range of $0.0791-0.3162 \mathrm{~kJ} / \mathrm{mol}$. Based on these data, it can thus be concluded that the effect of physical adsorption will play a dominating role in the adsorption process of CR and MO dyes onto the neem 
leaves derived adsorbents [21].

The correlation coefficient $\left(\mathrm{R}^{2}\right)$ values are a measure of goodness-of-fit. For the adsorption process from Harkins-Jura isotherm plot, the values of $\mathrm{R}^{2}$ decrease in the order NLP-CR $(0.9889)>$ NLP-MO (0.9837). The $\mathrm{R}^{2}$ values are generally good showing that the data fits the Harkins-Jura's linear model very well. Harkin-Jura adsorption isotherm accounts for multilayer adsorption and can be explained by the existence of a heterogeneous pore distribution [29].

The FTIR spectrum of the adsorbent before adsorption (Figure 6(a)) display a number of absorption peaks, characterizing the complexity and heterogeneity of its surface [16]. The bands at $3448 \mathrm{~cm}^{-1}$ representing bonded $\mathrm{OH}$ in the oxygen-containing functional groups. The positions of the $\mathrm{C}-\mathrm{H}\left(2920 \mathrm{~cm}^{-1}\right)$, aliphatic $\mathrm{C}-\mathrm{C}(1273$ $\left.\mathrm{cm}^{-1}\right)$ and aromatic $\mathrm{C}=\mathrm{C}\left(1604 \mathrm{~cm}^{-1}\right)$ and carboxylic/carbonyl $\left(1723 \mathrm{~cm}^{-1}\right)$ groups vibrations contributed by those in the structure of cellulose, hemicelluloses and lignin, which are common components of all plant materials, are indicated by the FTIR spectra of powdered neem-tree leaves [30].

The shifting or splitting of some peaks (changes in some vibration frequencies) after the adsorption process indicates chemical interaction taking place between the biomass and the dye [31].

Figures 7(a)-(c) elucidates the surface morphologies of the adsorbent before and after adsorption. Before

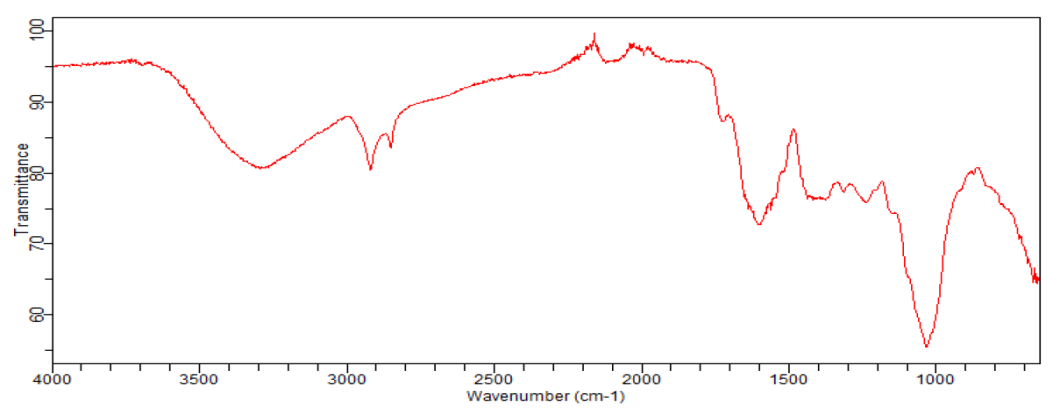

(a)

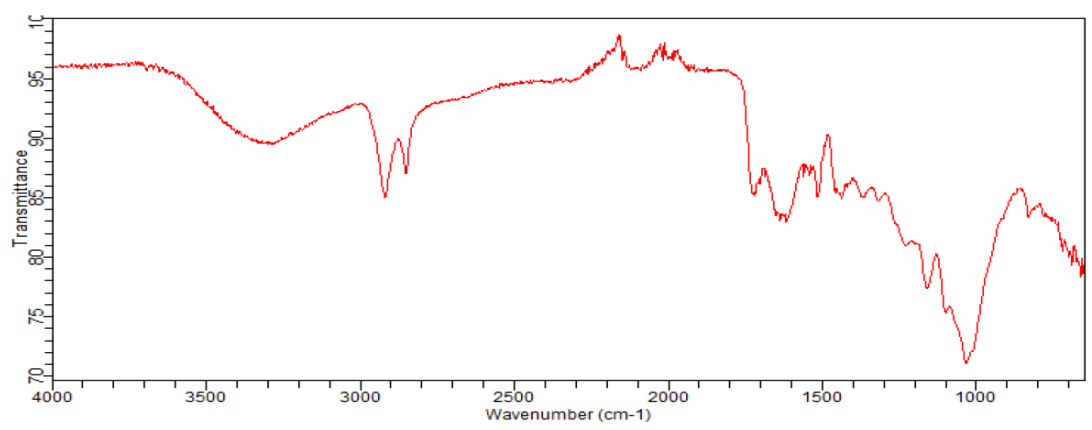

(b)

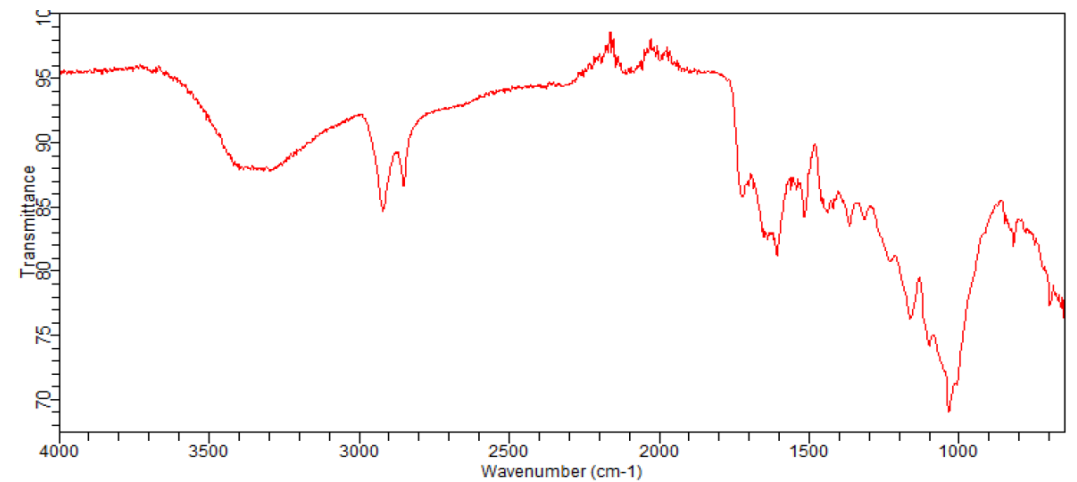

(c)

Figure 6. FTIR of Neem Leave Adsorbents: (a) (before adsorption); (b) and (c) (after Adsorption of Congo Red and Methyl Orange Respectively). 


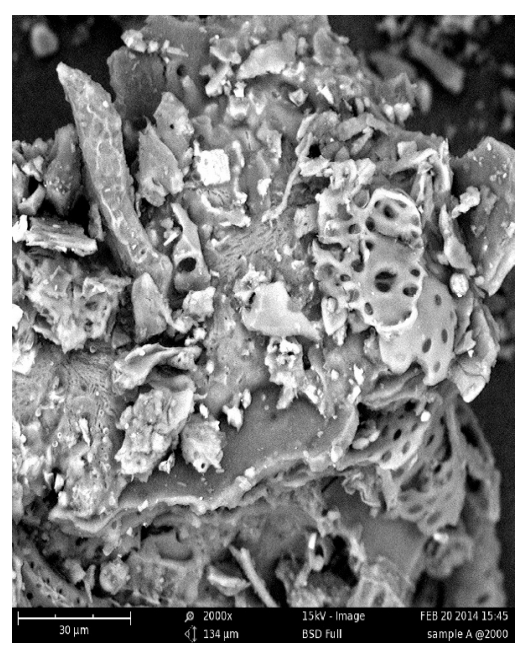

(a)

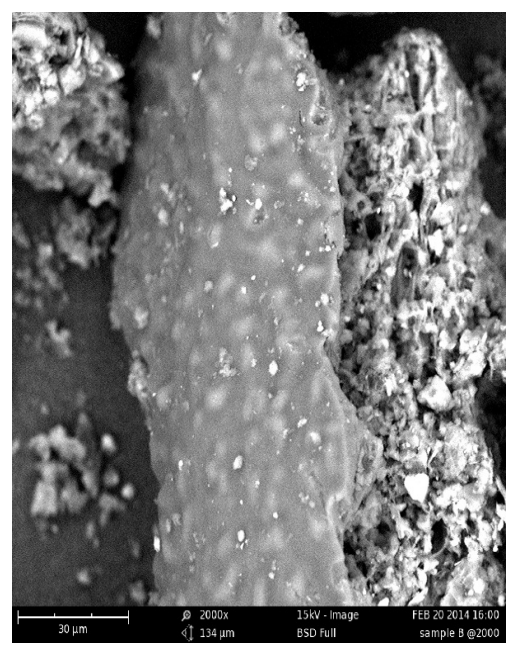

(b)

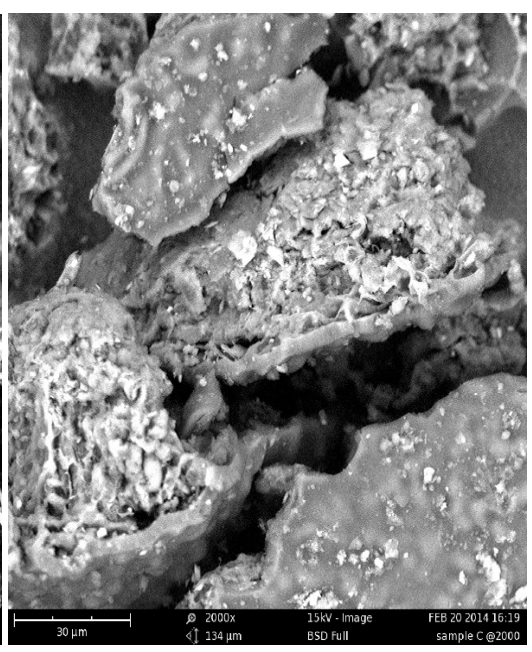

(c)

Figure 7. (a) NLP Before adsorption; (b) NLP After Adsorption of CR; (c) NLP After Adsorption of MO.

contact with the adsorbate the surface appears as a fibrous material with irregular macropores and some expanded cavities which may allow for the diffusion of the dye molecules through the macropores of the adsorbent. After the adsorption, the appearance of molecular cloud over the surface of adsorbent confirms the binding of dye ions onto the functional groups present in neem leave [31].

\section{Conclusion}

The research findings revealed the adsorption capabilities of the substrate and that the adsorption process may involved diffusion of the dye molecules into the adsorbent as observed from the SEM.

\section{References}

[1] Rijsberman, F.R. (2006) Water Scarcity: Fact or Fiction. Agricultural Water Management, 80, 5-22. http://dx.doi.org/10.1016/j.agwat.2005.07.001

[2] Ahuja, S. (2009) Handbook of Water Purity and Quality. IWA Publishing, Great Britain.

[3] Al-Asheh, S., Banat, F. and Abu-Aita, L. (2003) Adsorption of Phenol Using Different Types of Activated Bentonites. Separation and Purification Techniques, 33, 1-10. http://dx.doi.org/10.1016/S1383-5866(02)00180-6

[4] Santos, S.C.R. and Boaventura, R.A.R. (2008) Adsorption Modelling of Textile Dyes by Sepiolite. Applied Clay Science, 42, 137-145. http://dx.doi.org/10.1016/j.clay.2008.01.002

[5] Zohra, B., Aicha, K., Fatima, S., Nourredin, B. and Zoubir, D. (2008) Adsorption of Direct Red 2 on Bentonite Modified by Cetyltrimethylammonium Bromide. Chemical Engineering Journal, 136, 295-305. http://dx.doi.org/10.1016/j.cej.2007.03.086

[6] Gómez, V., Larrechi, M.S. and Callao, M.P. (2007) Kinetic and Adsorption Study of Acid Dye Removal Using Activated Carbon. Chemosphere, 69, 1151-1158. http://dx.doi.org/10.1016/j.chemosphere.2007.03.076

[7] Gupta, V.K., Kumar, R., Nayak, A., Saleh, T.A. and Barakat, M.A. (2013) Adsorptive Removal of Dyes from Aqueous Solution onto Carbon Nanotubes: A Review. Advances in Colloid and Interface Science, 193-194, 24-34. http://dx.doi.org/10.1016/j.cis.2013.03.003

[8] Acemioglu, B. (2004) Adsorption of Congo Red from Aqueous Solution onto Calcium-Rich Fly Ash. Journal of Colloid and Interface Science, 274, 371-379. http://dx.doi.org/10.1016/j.jcis.2004.03.019

[9] Purkait, M.K., Maiti, A., Das Gupta, S. and De, S. (2007) Removal of Congo Red Using Activated Carbon and Its Regeneration. Journal of Hazardous Materials, 145, 289-295. http://dx.doi.org/10.1016/j.jhazmat.2006.11.021

[10] Song, Y.L., Li, J.T. and Chen H. (2009) Degradation of C.I. Acid Red 88 Aqueous Solution by Combination of Fenton's Reagent and Ultrasound Irradiation. Journal of Chemical Technology and Biotechnology, 84, 578-583. http://dx.doi.org/10.1002/jctb.2083

[11] Liu, C., Ngo, H.H., Guo, W. and Tung, K. (2012) Optimal Conditions for Preparation of Banana Peels, Sugarcane Ba- 
gasse and Watermelon Rind in Removing Copper from Water. Bioresource Technology, 119, 349-354. http://dx.doi.org/10.1016/j.biortech.2012.06.004

[12] Yadla, S.V., Sridevi, V. and Lakshmi, M.V.V.C. (2012) A Review on Adsorption of Heavy Metals from Aqueous Solution. Journal of Chemical, Biological and Physical Sciences, 2, 1585-1593.

[13] Gönen, F. and Serin, D.S. (2012) Adsorption Study on Orange Peel: Removal of Ni (II) Ions from Aqueous Solution. African Journal of Biotechnology, 11, 1250-1258.

[14] Sharma, N., Tiwari, D.P. and Singh, S.K. (2012) Decolourization of Synthetic Dyes by Agricultural Waste-A Review. International Journal of Scientific \& Engineering Research, 3, 1-10. http://dx.doi.org/10.15373/22778179/MARCH2014/139

[15] Haddadian, Z., Shavandi, M.A., Abidin, Z.Z., Fakhru'l-Razi, A. and Ismail, M.H.S. (2013) Removal of Methyl Orange from Aqueous Solutions Using Dragon Fruit (Hylacereusundatus) Foliage. Chemical Science Transactions, 2, 900910.

[16] Suyamboo, B.K. and Perumal R.S. (2012) Equilibrium, Thermodynamic and Kinetic Studies on Adsorption of a Basic Dye by Citrullus lanatus Rind. Iranica Journal of Energy \& Environment, 3, 23-34. http://dx.doi.org/10.5829/idosi.ijee.2012.03.01.0130

[17] Gopalakrishnan, K., Manivannan, V. and Jeyadoss, T. (2010) Comparative Study of $\mathrm{Zn}(\mathrm{II}), \mathrm{Cu}(\mathrm{II}) \mathrm{and} \mathrm{Cr}(\mathrm{VI}) \mathrm{from}$ Textile Dye Effluent Using Sawdust and Neem Leaves Powder. E-Journal of Chemistry, 7, S504-S510. http://dx.doi.org/10.1155/2010/506424

[18] Lian, L., Guo, L. and Guo, C. (2009) Adsorption of Congo Red from Aqueous Solution on Cabentonite. Journal of Hazardous Materials, 161, 126-131. http://dx.doi.org/10.1016/j.jhazmat.2008.03.063

[19] Patil, S., Renukdas, S. and Patel, N. (2011) Removal of Methylene Blue from Aqueous Solutions by Adsorption Using Teak Tree (Tectona grandis) Bark Powder. International Journal of Environmental Sciences, 1, 711-725.

[20] Abdullah, N.M., Othaman, R., Abdullah, I., Jon, N. and Baharum, A. (2012) Studies on the Adsorption of Phenol Red Dye Using Silica-Filled enr/pvc Beads. Journal of Emerging Trends in Engineering and Applied Sciences, 3, 845-850.

[21] Liu, J. and Wang, X. (2013) Novel Silica-Based Hybrid Adsorbents: Lead(II) Adsorption Isotherms. The Scientific World Journal, 2013, Article ID: 897159. http://dx.doi.org/10.1155/2013/897159

[22] Bhattacharyya, K.G. and Sharma, A. (2004) Azadirachta indica Leaf Powder as an Effective Biosorbent for Dyes: A Case Study with Aqueous Congo Red Solutions. Journal of Environmental Management, 71, 217-229. http://dx.doi.org/10.1016/j.jenvman.2004.03.002

[23] Asiagwu, A.K., Omuku, P.E. and Alisa, C.O. (2012-2013) Kinetic Model for Removal of Methyl Orange (Dye) from Aqueous Solution Using Avocado Pear (Persea americana) Seed. Journal of Chemical, Biological and Physical Sciences, 3, 48-57.

[24] Shah, B.A., Shah, A.V. and Shah, P.M. (2011) Sorption Isotherms and Column Separation of Cu(II) and Zn(II) Using Ortho Substituted Benzoic Acid Chelating Resins. Archives of Applied Science Research, 3, 327-341.

[25] Samarghandi, M.R., Hadi, M., Moayedi, S. and Askari, F.B. (2009) Two-Parameter Isotherms of Methyl Orange Sorption by Pinecone Derived Activated Carbon. Iranica Journal of Environmental Health, Science and Engineering, 6, 285-294.

[26] Meroufel, B., Benali, O., Benyahia, M., Benmoussa, Y. and Zenasni, M.A. (2013) Adsorptive Removal of Anionic Dye from Aqueous Solutions by Algerian Kaolin: Characteristics, Isotherm, Kinetic and Thermodynamic Studies. Journal of Material and Environmental Science, 4, 482-491.

[27] Mumin, M.A., Khan, M.M.R., Akhter, K.F. and Uddin, M.J. (2007) Potentially of Open Burnt Clay as an Adsorbent for the Removal of Congo Red from Aqueous Solution. International Journal of Environmental Science and Technology, 4, 525-532. http://dx.doi.org/10.1007/BF03325990

[28] Jayaraj, R., Thanaraj, P.J., Natarajan, S.T. and Prasath, P.M.D. (2011) Removal of Congo Red Dye from Aqueous Solution Using Acid Activated Eco-Friendly Low Cost Carbon Prepared from Marine Algae Valoria bryopsis. Journal of Chemical and Pharmaceutical Research, 3, 389-396.

[29] Khan, T.A., Dahiya, S. and Imran Ali, I. (2012) Removal of Direct Red 81 Dye from Aqueous Solution by Native and Citric Acid Modified Bamboo Sawdust-Kinetic Study and Equilibrium Isotherm Analyses. Gazi University Journal of Science, 25, 59-87.

[30] Giwa, A.A., Bello, I.A. and Olajire, A.A. (2013) Removal of Basic Dye from Aqueous Solution by Adsorption on Melon Husk in Binary and Ternary Systems. Chemical and Process Engineering Research, 13, 51-68.

[31] Bharathi, K.S. and Ramesh, S.P.T. (2013) Fixed-Bed Column Studies on Biosorption of Crystal Violet from Aqueous Solution by Citrullus lanatus (Watermelon) Rind and Cyperus rotundus. Applied Water Science, 3, 673-687. http://dx.doi.org/10.1007/s13201-013-0103-4 